\title{
High efficacy of low-dose albumin infusion in the prevention of paracentesis-induced circulatory dysfunction
}

\author{
Ayman Alsebaey ${ }^{*}$ (D), Eman Rewisha and Imam Waked
}

\begin{abstract}
Background: Large-volume paracentesis (LVP) is a main pillar in treating patients with tense ascites. Without plasma expanders use, paracentesis-induced circulatory dysfunction (PICD) is a common complication with decreased survival. The aim was to compare low-dose albumin ( $2 \mathrm{~g} / \mathrm{L}$ ascitic fluid removed $n=85$ ) with standarddose albumin ( $6 \mathrm{~g} / \mathrm{L}$ ascitic fluid removed, $n=25$ ) for prevention of PICD. Liver function tests, urea, creatinine, CBC, and abdominal ultrasonography were done. Plasma renin activity (PRA) was measured at baseline and on the 6th day post-LVP. The delta change $(\Delta)=$ day 6 variable minus baseline variable value. PICD was defined as increase in PRA of $>50 \%$ of the baseline value.

Results: Patients in low-dose albumin group were mainly Child B compared with Child C (85.9\% vs. 52\%; $p=$ 0.001), underwent less paracentesis volume ( $9.78 \pm 3.56$ vs. $\left.12.52 \pm 3.6 L_{;} p=0.001\right)$, but had higher baseline PRA $(859.62 \pm 1151.34$ vs. $165.93 \pm 95.34 \mathrm{pg} / \mathrm{mL} ; p=0.001)$. In both groups, the PRA increased at day 6 compared with the baseline (1141.57 \pm 1433.01 vs. $859.62 \pm 1151.34 \mathrm{pg} / \mathrm{mL} ; p=0.01)$ and (192.21 \pm 80.99 vs. $165.93 \pm 95.34 \mathrm{pg} /$ $\mathrm{mL} ; p=0.01)$ respectively. Both groups were comparable for $\Delta$ PRA (281.95 $\pm 851.4 \mathrm{vs} .26 .28 \pm 30.2 \mathrm{pg} / \mathrm{mL} ; p=$ $0.102)$ and PRA percent increase (10.97 \pm 30.77 vs. $12.57 \pm 14.87 ; p=0.844)$. They had comparable PICD incidence (24.7\% vs. $12 \% ; p=0.27$ ). Females were more liable for PICD occurrence than males (OR 2.91, 95\% CI 1.125-7.547, $p$ $=0.028$ ) and so Child B patients than Child C (OR 8.4, 95\% Cl 1.072-65.767, $p=0.043$ ).
\end{abstract}

Conclusion: Low-dose albumin infusion is comparable to the standard-dose albumin for the prevention of PICD.

Keywords: Large-volume paracentesis, Ascites, Albumin, Paracentesis-induced circulatory dysfunction, Plasma renin activity

\section{Background}

Liver cirrhosis is the final station of many liver diseases. Clinically, it may be compensated then after a variable period being decompensated. The development of ascites is the main sign of decompensation [1]. Actually, ascites develops in $50 \%$ of the patients within 10 years of liver cirrhosis diagnosis. Ascites is associated poor survival where $50 \%$ of the patients survive for $2-5$ years [2].

Clinically, ascites is classified into 3 grades. The 1st and the 2nd one can be managed by salt restriction and diuretics, but the 3rd degree "tense" ascites is managed by large-volume paracentesis (LVP) followed by diuretics.

\footnotetext{
* Correspondence: aymanalsebaey@liver.menofia.edu.eg Department of Hepatology and Gastroenterology, National Liver Institute, Menoufia University, Shebeen El-Koom 32511, Egypt
}

About $20 \%$ of the patients who were diuretic responder will be diuretic resistant $[3,4]$.

Refractory ascites is a condition that is seen in $10 \%$ of patients with ascites. It is due to resistance to diuretics "diuretic-resistance ascites" or contraindication for diuretics "diuretic-intractable ascites". Until now, the main arms for the treatment of patients with tense or refractory ascites is LVP or transjugular intrahepatic portosystemic shunt (TIPS). Liver transplantation is the best solution. In fact, TIPS is associated with decreased demand for paracentesis, for nutritional improvement, and may be for survival benefit though it is associated with increased risk of encephalopathy. So, LVP is still the first option especially that TIPS is not widely available $[4,5]$.

Paracentesis-induced circulatory dysfunction (PICD) is a complication of LVP that is less seen if paracentesis is less 
than $5 \mathrm{~L}$. It is related to marked activation of the reninangiotensin and sympathetic nervous systems over the levels before paracentesis. It is preventable by plasma expanders use especially human albumin $(6-8 \mathrm{~g} / \mathrm{L}$ ascitic fluid removed). PICD is associated with rapid re-accumulation of ascites, dilutional hyponatremia, hepatorenal syndrome, and decreased survival [6].

Albumin is not a simple plasma expander but has other advantages as detoxification of reactive oxygen and nitrogen species, endothelial stabilization and platelet antiaggregation, and modulation of the immune and inflammatory responses [7]. The main drawback is that the drug is costly, so searching for alternatives is highly warranted [8].

This study aimed to compare low-dose albumin $(2 \mathrm{~g} / \mathrm{L}$ ascitic fluid removed) to standard-dose albumin $(6 \mathrm{~g} / \mathrm{L}$ ascitic fluid removed) for the prevention of PICD.

\section{Methods}

In our previous study [8], we compared terlipressin (3 mg IV), hydroxyethyl starch (HES 130/0.4; $8 \mathrm{~g} / \mathrm{L}$ ascitic fluid removed), oral midodrine (5-10 mg daily), low-dose albumin ( $2 \mathrm{~g} / \mathrm{L}$ ascitic fluid removed), and standard-dose albumin (6 $\mathrm{g} / \mathrm{L}$ ascitic fluid removed) for PICD prevention. All groups were equal for PICD development. In this study, we could increase the number of patients in low-dose albumin group.

This study was conducted in National Liver Institute hospitals, hepatology, and gastroenterology department, Menoufia University. Prior institutional review board approval was acquired, and then an informed consent was obtained from all enrolled patients.

Patients who were requiring LVP for tense ascites $(n=$ 110) were included in the study. Liver cirrhosis was diagnosed according to the clinical, laboratory, and abdominal ultrasonography findings [9].

Patients with the following criteria were included: tense ascites requiring LVP, age 18-70 years old, absence of cardiac disease, respiratory disease, hepatic encephalopathy, sepsis, spontaneous bacterial peritonitis, renal impairment (serum creatinine > $1.5 \mathrm{mg} / \mathrm{dL}$ ), and gastrointestinal hemorrhage within 7 days before the study. All patients were on a low-sodium diet $(34 \mathrm{mmol} /$ day) for at least 7 days outpatient before inclusion in the study.

On day 0 , a baseline workup, including body weight, mean arterial pressure (MAP), heart rate, electrocardiogram, liver tests (bilirubin, albumin, AST, ALT, alkaline phosphatase), and renal function tests (urea and creatinine), were conducted. Blood samples were collected after an overnight fast and bed rest for at least $30 \mathrm{~min}$ in the supine position for measuring PRA. Blood samples were put into chilled ethylenediaminetetraacetic acid tubes, centrifuged at $2500 \mathrm{rpm}$ for $10 \mathrm{~min}$ at $-3{ }^{\circ} \mathrm{C}$, and stored at $-20{ }^{\circ} \mathrm{C}$. Total paracentesis was then done under local anesthesia and strict aseptic conditions.
Patients were categorized into 2 groups: low-dose albumin ( $2 \mathrm{~g} / \mathrm{L}$ ascitic fluid removed; $n=85$ ) and standard-dose albumin (6 g/L ascitic fluid removed; $n=25)$. Human albumin (20\%; infusion solution; DRK-Blutspendedienst NSTOB 31830 Springe; each $1000 \mathrm{ml}$ containing $200 \mathrm{~g}$ of human albumin) was used. Fifty percent of the dose was given within $2 \mathrm{~h}$ and the remainder $6 \mathrm{~h}$ after the procedure if more than $150 \mathrm{~mL}$ was infused to avoid pulmonary edema.

From day 1 to day 5, the patients were monitored daily for body weight, daily urine output volume, blood pressure, heart rate, and development of complications. On the day of hospital discharge (day 6), blood pressure, heart rate, and weight were recorded. Electrocardiogram, renal, and liver function tests were done, and blood was collected for PRA. Changes of the effective arterial blood volume were evaluated by measuring plasma rennin activity (PRA) on the day of paracentesis (day 0; baseline) and on the day of hospital discharge (day 6).

The primary end point was taken as development of PICD that was defined as an increase in PRA of $>50 \%$ of the baseline value [10]. PRA was laboratory measured in accord with Alsebaey et al [8].

\section{Statistical analysis}

Data was statistically analyzed using $\mathrm{IBM}^{\star} \mathrm{SPSS}^{\oplus}$ Statistics $^{\circ}$ version 21 for Windows (IBM Corporation, Armonk, New York, USA). Data are expressed as mean \pm standard deviation for parametric data, number with column percentage for nominal data, and the range for non-parametric data. All $p$ values are two tailed, with values $<0.05$ considered statistically significant. Comparisons between two groups were performed using the Student's $t$ test for parametric data, and Mann-Whitney test for nonparametric data. Comparisons of the variables treatment induced change in the same group were performed using the paired $t$ test for parametric data and Wilcoxon signed ranks test for nonparametric data. Chi-squared test $\left(x^{2}\right)$ and Fisher exact test for categorical data analysis. Univariate and multivariate binary logistic regression was done for detecting the predictors of PICD.

\section{Results}

Table 1 shows the baseline data in both groups. There was a statistically significant difference $(p<0.05)$ between both groups as regards the Child Pugh class, paracentesis volume, baseline serum albumin, and baseline PRA.

Patients who underwent low-dose albumin infusion post-paracentesis were mainly Child Pugh class B in contrast to patients in the other group (85.9\% vs. $52 \%$; $p$ $=0.001)$, underwent less average paracentesis volume $(9.78 \pm 3.56(7-25 \mathrm{~L})$ vs. $12.52 \pm 3.6(6-20 \mathrm{~L}) ; p=$ $0.001)$, less baseline serum albumin $(2.20 \pm 0.36$ vs. 2.55 $\pm 0.6 \mathrm{~g} / \mathrm{dL} ; p=0.002)$, but higher baseline PRA (859.62 \pm 1151.34 vs. $165.93 \pm 95.34 \mathrm{pg} / \mathrm{mL} ; p=0.001)$. 
Table 1 Comparison of the baseline parameters in both groups

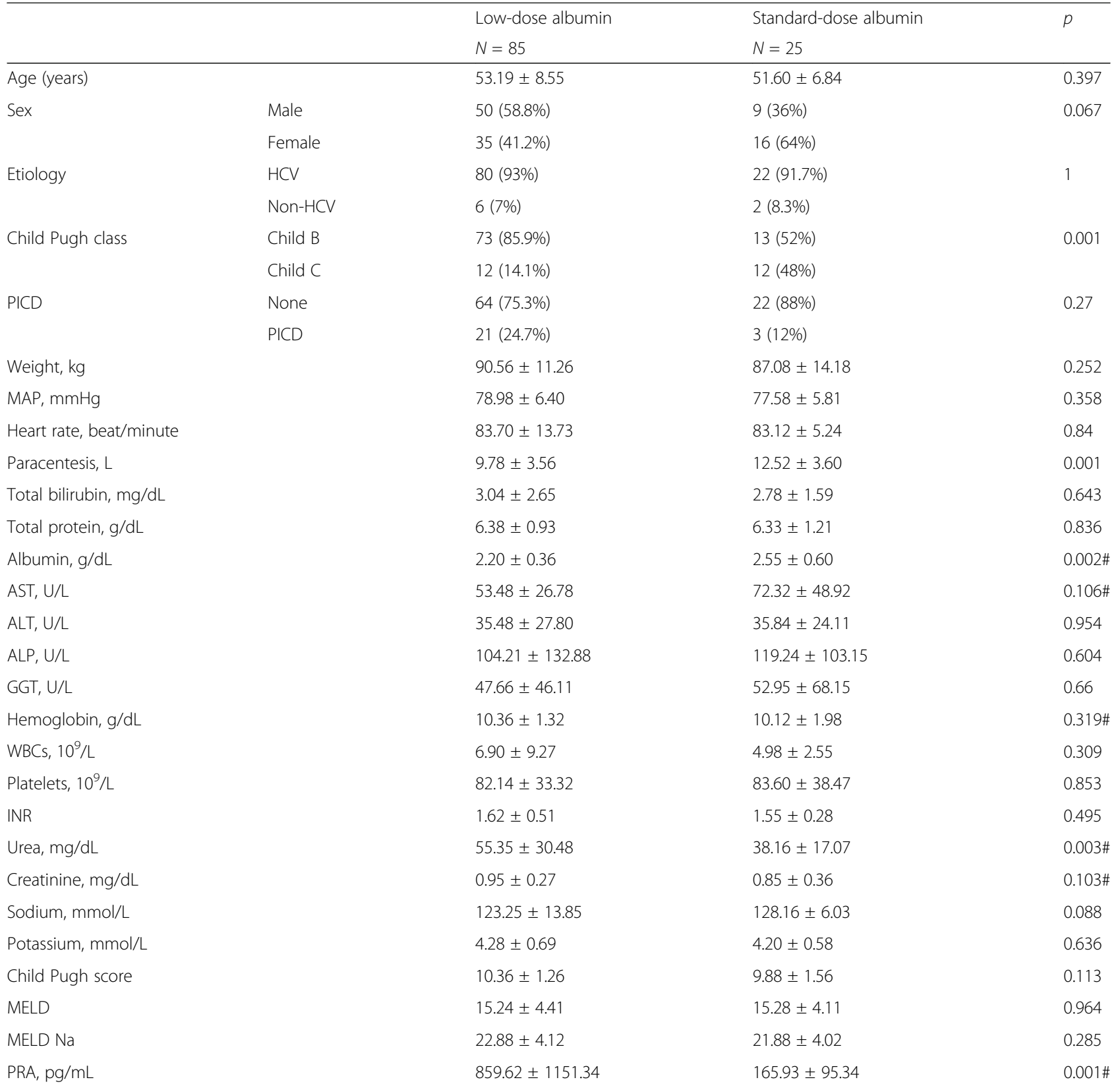

PICD paracentesis-induced circulatory dysfunction, MAP mean arterial pressure, PRA plasma renin activity, HCV hepatitis C virus, MELD model for end-stage liver disease

"Mann-Whitney $U$ test

The other parameters did not show statistically significant difference $(p>0.05)$, namely age, sex, weight, MAP, heart rate, serum bilirubin, serum total protein, AST, ALT, ALP, GGT, hemoglobin, WBCs, platelets, INR, blood urea, serum creatinine, sodium, potassium, MELD, and MELD Na score.

The delta change $(\Delta)=$ day 6 variable value minus baseline variable value. Positive delta means higher day 6 value than baseline and vice versa. There was a statistically significant difference $(p<0.05)$ between both groups as regards the $\Delta$ weight and $\Delta$ blood urea (Table 2). Patients underwent low-dose albumin infusion post-paracentesis had less drop in the weight $(-4.35 \pm 7.02$ vs. $-10.64 \pm$ $3.67 \mathrm{~kg} ; p=0.001)$ but higher blood urea increase (14.96 \pm 23.84 vs. $3.72 \pm 10.62 \mathrm{mg} / \mathrm{dL} ; p=0.005)$.

Delta MAP, heart rate, serum bilirubin, serum total protein, serum albumin, AST, ALT, ALP, GGT, hemoglobin, WBCs, platelets, INR, serum creatinine, sodium, potassium, model of end-stage liver disease (MELD), and MELD Na score did not show a statistically significant difference $(p>0.05)$ between both groups. 
Table 2 Comparison of treatment induced changes in both groups

\begin{tabular}{|c|c|c|c|}
\hline & Low-dose albumin & Standard-dose albumin & $p$ \\
\hline & $N=85$ & $N=25$ & \\
\hline$\Delta$ Weight, $\mathrm{kg}$ & $-4.35 \pm 7.02$ & $-10.64 \pm 3.67$ & $0.001 \#$ \\
\hline$\triangle \mathrm{MAP}, \mathrm{mmHg}$ & $-1.59 \pm 9.29$ & $-1.19 \pm 6.09$ & $0.699 \#$ \\
\hline$\Delta$ Heart rate, beat/minute & $2.07 \pm 14.14$ & $0.80 \pm 3.18$ & $0.523 \#$ \\
\hline$\Delta$ Total bilirubin, $\mathrm{mg} / \mathrm{dL}$ & $0.15 \pm 0.89$ & $0.12 \pm 0.59$ & $0.756 \#$ \\
\hline$\Delta$ Total protein, g/dL & $-0.12 \pm 0.49$ & $-0.28 \pm 0.85$ & 0.249 \\
\hline$\Delta$ Albumin, $\mathrm{g} / \mathrm{dL}$ & $-0.01 \pm 0.19$ & $2.35 \pm 11.56$ & $0.65 \#$ \\
\hline$\Delta \mathrm{AST}, \mathrm{U} / \mathrm{L}$ & $-0.95 \pm 24.65$ & $0.80 \pm 25.02$ & 0.756 \\
\hline$\Delta \mathrm{ALT}, \mathrm{U} / \mathrm{L}$ & $-2.34 \pm 24.98$ & $2.44 \pm 12.10$ & 0.358 \\
\hline$\Delta \mathrm{ALP}, \mathrm{U} / \mathrm{L}$ & $-12.06 \pm 114.57$ & $-31.12 \pm 106.93$ & 0.46 \\
\hline$\Delta \mathrm{GGT}, \mathrm{U} / \mathrm{L}$ & $-1.72 \pm 20.57$ & $-7.86 \pm 72.38$ & 0.486 \\
\hline$\Delta$ Urea, mg/dL & $14.96 \pm 23.84$ & $3.72 \pm 10.62$ & $0.005 \#$ \\
\hline$\Delta$ Creatinine, $\mathrm{mg} / \mathrm{dL}$ & $0.14 \pm 0.35$ & $0.06 \pm 0.29$ & $0.348 \#$ \\
\hline$\Delta$ Sodium, mmol/L & $-1.84 \pm 17.39$ & $-2.72 \pm 1.43$ & 0.8 \\
\hline$\Delta$ Potassium, $\mathrm{mmol} / \mathrm{L}$ & $0.07 \pm 0.69$ & $-0.14 \pm 0.64$ & 0.166 \\
\hline$\Delta$ MELD & $0.79 \pm 3.46$ & $0.12 \pm 1.59$ & $0.145 \#$ \\
\hline$\Delta \mathrm{PRA}, \mathrm{pg} / \mathrm{mL}$ & $281.95 \pm 851.4$ & $26.28 \pm 30.2$ & $0.102 \#$ \\
\hline PRA percent increase & $10.97 \pm 30.77$ & $12.57 \pm 14.87$ & $0.844 \#$ \\
\hline
\end{tabular}

$\triangle$ indicates day 6 values to day 1 value

$M A P$ mean arterial pressure, PRA plasma renin activity

"Mann-Whitney $U$ test

Tables 1 and 2 and Figs. 1 and 2 showed the PICD studied parameters. Patients in the low-dose albumin group had higher baseline PRA $(859.62 \pm 1151.34$ vs. $165.93 \pm 95.34 \mathrm{pg} / \mathrm{mL} ; p=0.001$ ) (Table 1 ). In both lowdose and standard-dose albumin groups, the PRA increased at day 6 compared with the baseline (1141.57 \pm 1433.01 vs. $859.62 \pm 1151.34 \mathrm{pg} / \mathrm{mL} ; p=0.01)$ and $(192.21 \pm 80.99$ vs. $165.93 \pm 95.34 \mathrm{pg} / \mathrm{mL} ; p=0.01)$ respectively (Fig. 1). Both the low-dose and standard-dose albumin groups were comparable for $\triangle$ PRA (281.95 \pm 851.4 vs. $26.28 \pm 30.2 \mathrm{pg} / \mathrm{mL} ; p=0.102$ ) (Table 2, Fig. 1 ), and PRA percent increase (10.97 \pm 30.77 vs. $12.57 \pm 14.87$; $p=0.844$ ) respectively (Fig. 1). By application of the PICD definition [10], both low-dose and standard-dose albumin groups had comparable PICD incidence (24.7\% vs. $12 \%$; $p$ $=0.27$ ) (Fig. 2).

The univariate binary regression analysis (Table 3) showed that females were more liable for PICD occurrence than males (OR 2.91, 95\% CI 1.125-7.547, $p=$ 0.028 ) and so Child Pugh class B patients than class $C$ (OR 8.4, 95\% CI: 1.072-65.767, $p=0.043$ ). The multivariate binary regression found also that females were more liable for PICD occurrence than males (OR 3.07, 95\% CI: $1.155-8.162, p=0.025)$ and so Child Pugh class B patients than class C (OR 8.92, 95\% CI: 1.120-71.118, $p=0.039)$.

On comparison of the two current studies groups with previously published data [8] as shown in Table 4 and
Fig. 3, all groups namely terlipressin, HES 130/0.4, midodrine, low-dose albumin, and standard-dose albumin were equal in the prevention of PICD $(p>0.05)$.

\section{Discussion}

The main concept of PICD pathogenesis is circulatory disturbance that develops after LVP if plasma expanders are not used. Immediately after LVP, there is decreased abdominal pressure, increased venous return, increased cardiac output, and suppression of the renin-angiotensin-sympathetic system. After $12 \mathrm{~h}$, if no plasma expanders are used, the opposite occurs with marked activation of the reninangiotensin-sympathetic system with reduced cardiac output. PICD may not be mere circulatory derangement [6]. In fact, Carl et al [11] in a small study $(n=10)$ hypothesized that LVP-induced hypotension increased bacterial translocation, innate immune activation that is responsible of vasodilation and subsequent PICD development.

PICD development is unrelated to the paracentesis flow rate [12]. Sersté et al [13] accused Beta blockers in the development of PICD in a small number study $(n=$ 10). PICD can be prevented by either plasma expanders or finding other solutions to avoid or replace LVP which is the accused factor.

Regarding avoiding LVP, TIPS is a good solution since it modifies the pathogenesis of ascites and improves the quality of life and survival. Unfortunately, the increased 

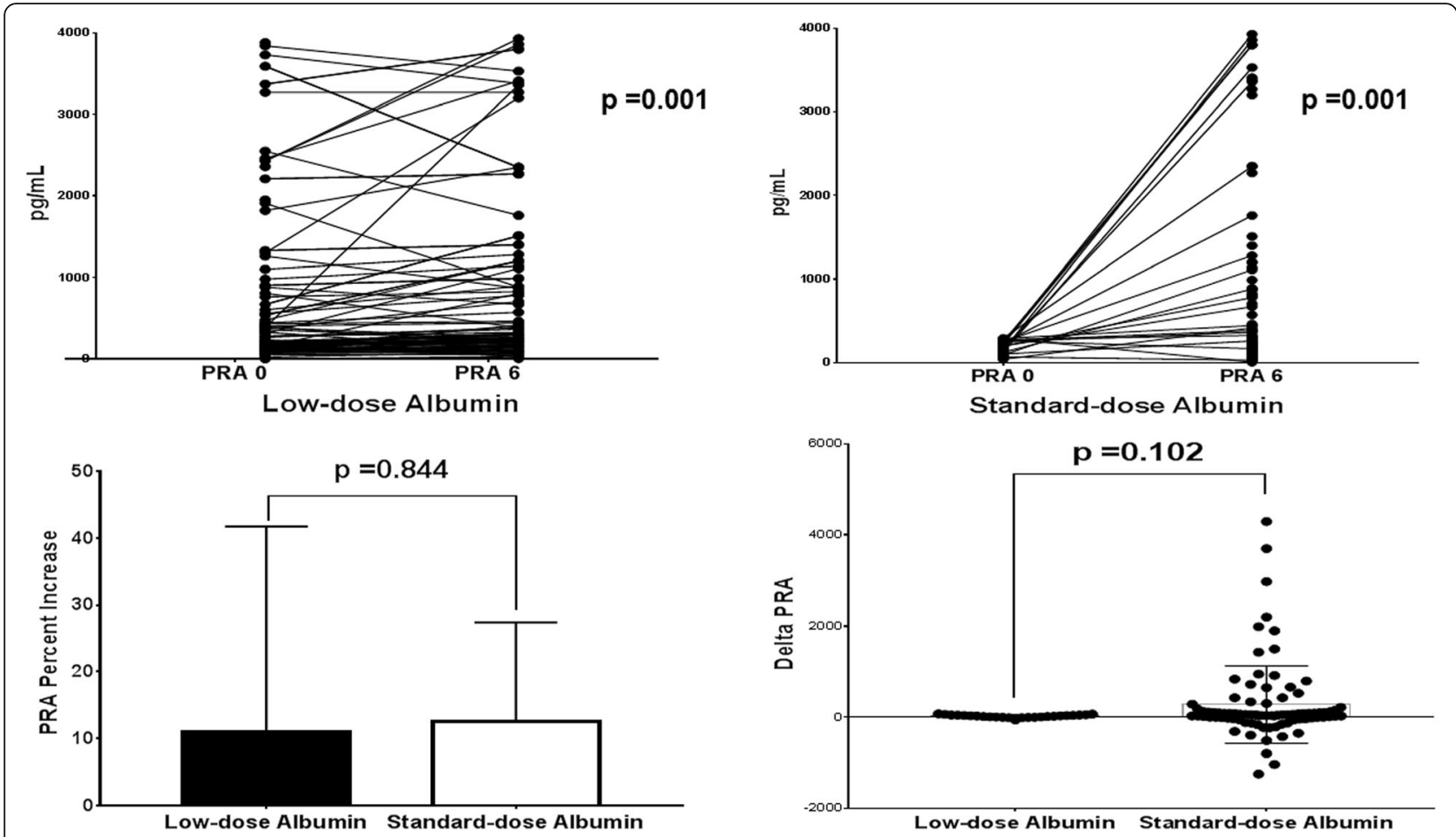

Fig. 1 Plasma renin activity (PRA) panel (days 0 and 6, delta change, percent increase) in low- and standard-dose albumin (Mann-Whitney $U$ test and Wilcoxon signed ranks test)

incidence of hepatic encephalopathy is a drawback [4]. Permanent-tunneled peritoneal catheter is a new modality to avoid LVP [14]. It is not associated with renal impairment but further studies are needed. Alfa pump is another new modality "low flow pump system" for the treatment of refractory ascites [15-17]. It pumps the ascitic fluid through a valve to the urinary bladder and gets out by urination. It is considered continuous lowvolume paracentesis. It decreased the ascites grade and the LVP times $[15,16]$. Bureau et al [17] compared alfa pump to standard of care LVP with albumin replacement. Patients who underwent alfa pump had a marked decreased need for LVP, improved quality of life, and nutritional status but unfortunately increased the adverse effects especially early acute kidney injury. Both groups had the same survival. The enthusiasm for alfa pump will fades with the small number study $(n=10)$ by Solà et al [18]. They followed up the patients for 1 year with measure of the glomerular filtration rate by isotopes, blood pressure, and activity of vasoconstrictor

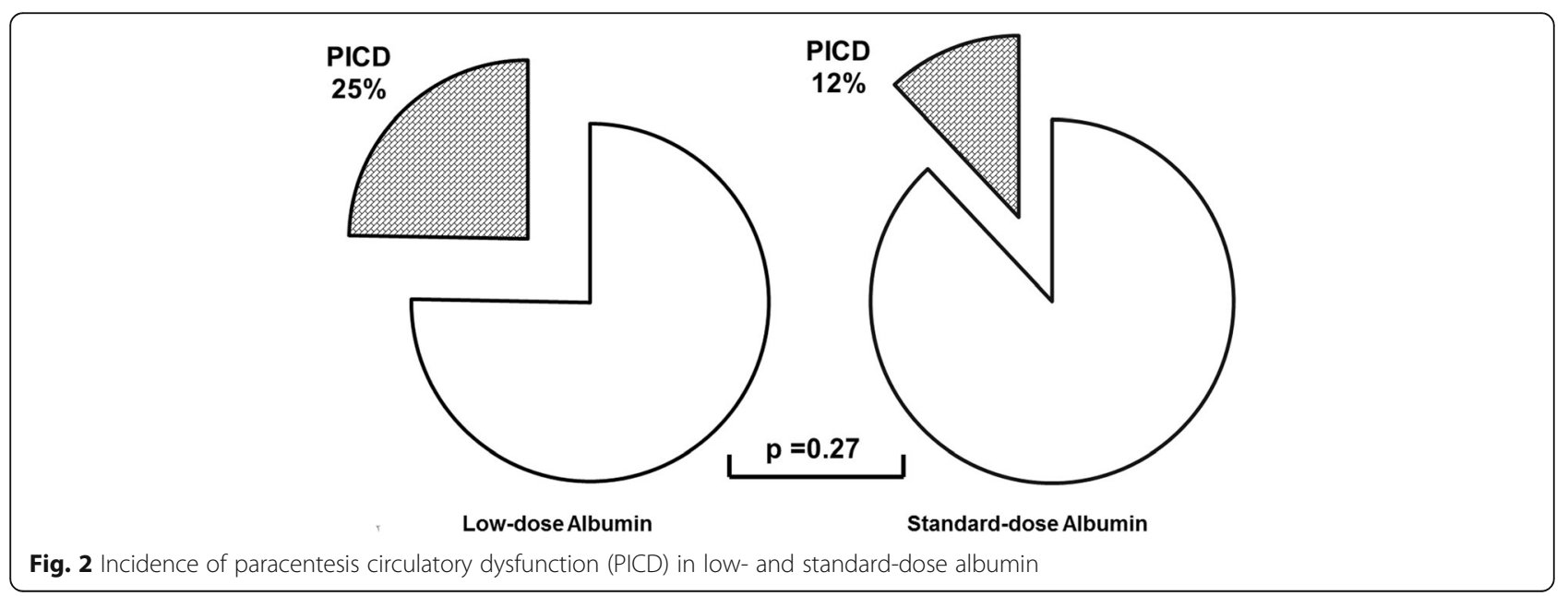


Table 3 Univariate and multivariate analysis of predictors of PICD occurrence

\begin{tabular}{|c|c|c|c|c|c|c|c|c|}
\hline & Univaria & & & & Multi & & & \\
\hline & $B$ & p & OR & $95 \% \mathrm{Cl}$ & $B$ & p & OR & $95 \% \mathrm{Cl}$ \\
\hline Age & -0.01 & 0.737 & 0.99 & $0.937-1.047$ & & & & \\
\hline Females & 1.07 & 0.028 & 2.91 & $1.125-7.547$ & 1.12 & 0.025 & 3.07 & $1.155-8.162$ \\
\hline Child Pugh B & 2.13 & 0.043 & 8.40 & $1.072-65.767$ & 2.19 & 0.039 & 8.92 & $1.120-71.118$ \\
\hline MAP, mmHg & 0.03 & 0.505 & 1.03 & $0.940-1.133$ & & & & \\
\hline Low-dose albumin & 0.88 & 0.187 & 2.41 & $0.654-8.857$ & & & & \\
\hline Paracentesis liters & 0.00 & 0.970 & 1.00 & $0.883-1.127$ & & & & \\
\hline Total bilirubin & -0.06 & 0.545 & 0.94 & $0.768-1.149$ & & & & \\
\hline Albumin & 0.41 & 0.408 & 1.51 & $0.567-4.038$ & & & & \\
\hline Urea & 0.01 & 0.238 & 1.01 & $0.994-1.023$ & & & & \\
\hline Creatinine & 0.28 & 0.725 & 1.32 & $0.281-6.216$ & & & & \\
\hline Sodium & -0.03 & 0.183 & 0.97 & $0.937-1.012$ & & & & \\
\hline MELD & -0.01 & 0.919 & 0.99 & $0.895-1.105$ & & & & \\
\hline MELD Na & 0.00 & 0.942 & 1.00 & $0.899-1.122$ & & & & \\
\hline
\end{tabular}

MAP mean arterial pressure, $O R$ odds ratio, $C I$ confidence interval, MELD model for end-stage liver disease, Na sodium

systems. The patients had significant decreased glomerular filtration rate at the 6th month and marked increase of PRA and norepinephrine concentration, with increased incidence of acute kidney injury. These features actually mimic PICD.

Tan et al [19] studied subtotal LVP not exceeding 8 L with using standard-dose albumin (6 g/L ascitic fluid removed; $n=57$ ) as a method for PICD prevention. They used plasma active renin instead of PRA. PICD was detected in $40.3 \%$ of patients. The MAP decreased at day 6 compared with the baseline in patients with and without PICD. Though they had comparable baseline and day 6, creatinine with no renal impairment was noted. These patients were followed up 24 months. They had comparable serial creatinine values; same risk of hospitalization, spontaneous bacterial peritonitis, other infections, or gastrointestinal bleeding; and finally same survival.

IV albumin infusion (6-8 $\mathrm{g} / \mathrm{L}$ ascitic fluid removed) is the standard of care plasma expander to prevent PICD. But it is associated with increased cost, so finding alternatives is warranted. Various drugs were studied like terlipressin [8, 2023], noradrenaline [20, 24], midodrine [8, 25-27], synthetic colloids [8, 28-34], and saline [35, 36]. Our previous study [8] is the first study to our knowledge that did head-to-head drug comparison. All previous studies compared the used drug, e.g., terlipressin to the standard of care IV albumin. In our previous study, we compared terlipressin, midodrine, HES 130/0.4, and low-dose albumin (2 g/L ascitic fluid removed) to the standard-dose albumin $(6 \mathrm{~g} / \mathrm{L}$ ascitic fluid removed). The incidence of PICD was comparable in all groups, suggesting that albumin alternatives could be used.

Why returning back to albumin? The study of Carl et al [11] suggested that there are bacterial translocation and innate immune activation that play a role in PICD development. Since albumin has antioxidant, immunomodulatory effect in addition to increased oncotic pressure [37], it will be the preferred drug in such condition. To skip the high cost of albumin, using low doses may be of benefit.

Alessandria et al [38] was the first researcher who suggested the use of low-dose albumin. She compared lowdose albumin ( $4 \mathrm{~g} / \mathrm{L}$ ascitic fluid removed; $n=35)$ with standard-dose albumin ( $8 \mathrm{~g} / \mathrm{L}$ ascitic fluid removed; $n=$ $35)$. Both groups were comparable for PICD development (14\% vs $20 \%)$ respectively and 6-month survival or recurrence of ascites. The second study was conducted by Alsebaey et al [8]. One arm was low-dose albumin (2 $\mathrm{g} / \mathrm{L}$ ascitic fluid removed; $n=25$ ) which is the lowest tested dose compared with other studies [38, 39]. The

Table 4 Comparison of different treatment protocols for the PICD prevention

\begin{tabular}{lllllll}
\hline & Terlipressin & HES 130/0.4 & Midodrine & Low-dose albumin & \multicolumn{2}{l}{ Standard-dose albumin } \\
& & $N(\%)$ & $N(\%)$ & $N(\%)$ & $N(\%)$ & $N(\%)$ \\
\hline PICD & None & $23(92 \%)$ & $23(92 \%)$ & $20(80 \%)$ & $64(75.3 \%)$ & $22(88 \%)$ \\
& PICD & $2(8 \%)$ & $2(8 \%)$ & $5(20 \%)$ & $21(24.7 \%)$ & $3(12 \%)$ \\
\hline
\end{tabular}

PICD paracentesis-induced circulatory dysfunction 


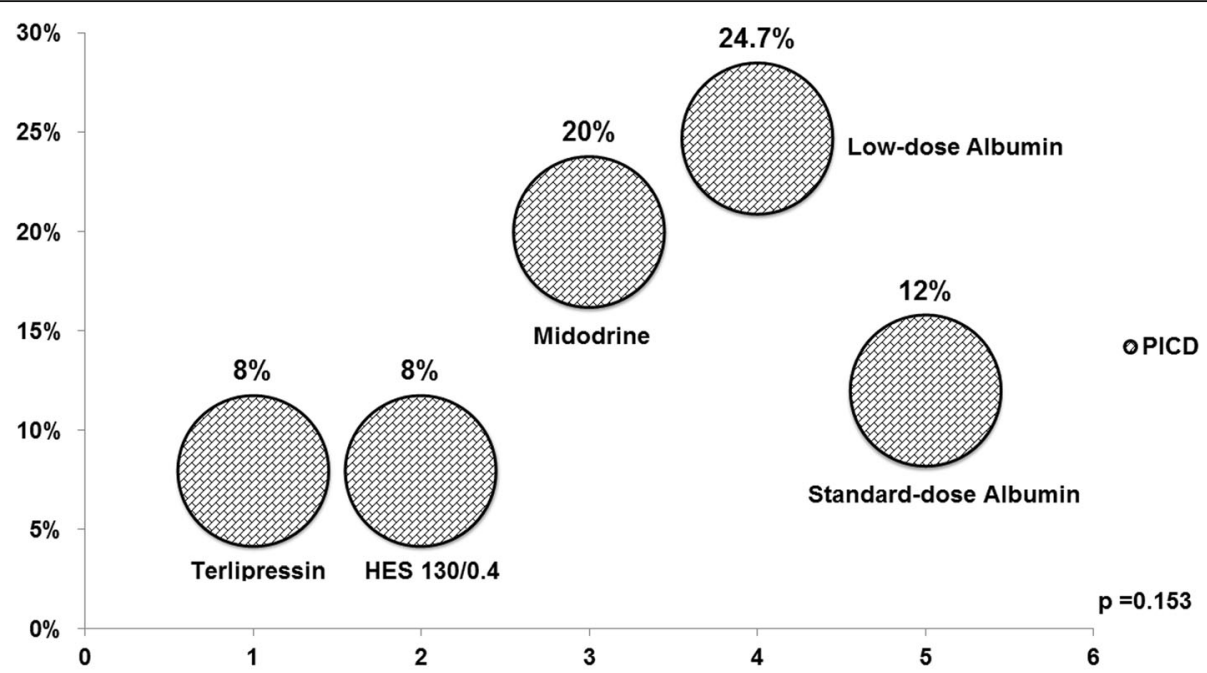

Fig. 3 Incidence of paracentesis circulatory dysfunction (PICD) in different groups, namely terlipressin, HES 130/0.4, midodrine, and low- and standard-dose albumin

PICD incidence in low-dose albumin was comparable to standard-dose albumin $(6 \mathrm{~g} / \mathrm{L}$ ascitic fluid removed; $n=$ $35)$, HES 130/0.4, midodrine, and terlipressin. The third study was conducted by Hussain et al [39] on the utility of low-dose albumin ( $4 \mathrm{~g} / \mathrm{L}$ ascitic fluid removed) on the prevention of paracentesis induced renal impairment. Actually, he did not measure PRA; he just followed up serum creatinine and sodium. Furthermore, he did not have arm of standard-dose albumin. He compared the utility of low-dose albumin in the prevention of renal impairment in patients who underwent low-volume paracentesis $(6.2 \pm 1 \mathrm{~L})$ and large-volume paracentesis $(10.4 \pm 1.5 \mathrm{~L})$. Few patients developed renal impairment $(4.62 \%$ vs. $6.45 \%)$ respectively.

In the current study, only blood urea increased from baseline to the 6th day especially in the low-dose albumin compared with the standard-dose albumin in contrast to creatinine which was not affected. The PRA increased in both groups, but the delta change and the percent increase were comparable in both groups. In addition, the PICD development was comparable in both groups. Females and Child Pugh class B patients were more liable for PICD development. When we compared the current two arms with the old arms in our previous study [8], the incidence of PICD was comparable in the five groups, namely terlipressin, HES 130/0.4, low-dose albumin ( $2 \mathrm{~g} / \mathrm{L}$ ascitic fluid removed), and the standarddose albumin $(6 \mathrm{~g} / \mathrm{L}$ ascitic fluid removed).

The limitations of the current study are being single center experience, have relative small number of patients, and have absence of longitudinal follow-up to calculate the incidence of renal impairment, infections, bleeding, and importantly the survival.

\section{Conclusion}

Low-dose albumin infusion is comparable to the standard-dose albumin for the prevention of PICD. Furthermore, it is equivalent to terlipressin, midodrine, and HES 130/0.4 for PICD prevention.

\section{Abbreviations}

LVP: Large-volume paracentesis; MAP: Mean arterial pressure; MELD: Model of end stage liver disease; PICD: Paracentesis-induced circulatory dysfunction; PRA: Plasma renin activity; TIPS: Transjugular intrahepatic portosystemic shunt

\section{Acknowledgements}

None

\section{Authors' contributions}

Data collection was contributed by AA, HMA, and MAE. Study design was done by AA, HMA, and MAE. Manuscript writing and final revision was performed by AA. All authors have read and approved the final manuscript.

\section{Funding}

None

Availability of data and materials

The datasets used and/or analyzed during the current study available from the corresponding author on reasonable request.

Ethics approval and consent to participate

It is approved by National Liver Institute IRB 0088/2014. Informed written consent was signed by all patients.

Consent for publication

Not applicable

\section{Competing interests}

Imam Waked is an investigator and/or speaker for Abbvie, Gilead Sciences, Janssen, Marcyrl, Onxio, and Pharco. The rest of the authors declare that they have no competing interests. 
Received: 14 October 2019 Accepted: 27 January 2020

\section{Published online: 15 April 2020}

\section{References}

1. D'Amico G, Garcia-Tsao G, Pagliaro L (2006) Natural history and prognostic indicators of survival in cirrhosis: a systematic review of 118 studies. J Hepatol 44:217-231

2. Kawaratani H, Fukui H, Yoshiji H (2017) Treatment for cirrhotic ascites. Hepatol Res 47:166-177

3. Solà E, Solé C, Ginès P (2016) Management of uninfected and infected ascites in cirrhosis. Liver Int 36:109-115

4. Annamalai A, Wisdom L, Herada M, Nourredin M, Ayoub W, Sundaram V et al (2016) Management of refractory ascites in cirrhosis: are we out of date? World J Hepatol 8:1182-1193

5. Salerno F, Guevara M, Bernardi M, Moreau R, Wong F, Angeli P et al (2010) Refractory ascites: pathogenesis, definition and therapy of a severe complication in patients with cirrhosis. Liver Int 30:937-947

6. Sola-Vera J, Such J (2004) Understanding the mechanisms of paracentesisinduced crculatory dysfunction. Eur J Gastroenterol Hepatol 16:295-298

7. Caraceni P, Angeli P, Prati D, Bernardi M, Alessandria C, Riggio O et al (2016) AISF-SIMTI position paper: the appropriate use of albumin in patients with liver cirrhosis. Dig Liver Dis 48:4-15

8. Alsebaey A, Abdel-Razek W, Bassuni A, Rewisha E, Khalil M, Waked I (2013) Prevention of paracentesis-induced circulatory dysfunction: could we use other albumin alternatives? Egyptian Liver Journal 3:118-125

9. Schuppan D, Afdhal NH (2008) Liver cirrhosis. Lancet 371:838-851

10. Ruiz-del-Arbol L, Monescillo A, Jimenez W, Garcia-Plaza A, Arroyo V, Rodes J (1997) Paracentesis-induced circulatory dysfunction: mechanism and effect on hepatic hemodynamics in cirrhosis. Gastroenterology 113:579-586

11. Carl DE, Ghosh S, Cheng J, Gehr TWB, Stravitz RT, Sanyal A (2014) Postparacentesis circulatory derangements are related to monocyte activation. Liver Int 34:1001-1007

12. Elsabaawy MM, Abdelhamid SR, Alsebaey A, Abdelsamee E, Obada MA, Salman TA et al (2015) The impact of paracentesis flow rate in patients with liver cirrhosis on the development of paracentesis induced circulatory dysfunction. Clin Mol Hepatol 21:365-371

13. Sersté T, Francoz C, Durand F, Rautou P-E, Melot C, Valla D et al (2011) Betablockers cause paracentesis-induced circulatory dysfunction in patients with cirrhosis and refractory ascites: a cross-over study. J Hepatol 55:794-799

14. Solbach P, Höner zu Siederdissen C, Taubert R, Ziegert S, Port K, Schneider A et al (2017) Home-based drainage of refractory ascites by a permanenttunneled peritoneal catheter can safely replace large-volume paracentesis. Eur J Gastroenterol Hepatol 29:539-546

15. Bellot $P$, Welker $M-W$, Soriano $G$, von Schaewen $M$, Appenrodt B, Wiest $R$ et al (2013) Automated low flow pump system for the treatment of refractory ascites: a multi-center safety and efficacy study. J Hepatol 58:922927

16. Thomas MN, Sauter GH, Gerbes AL, Stangl M, Schiergens TS, Angele M et al (2015) Automated low flow pump system for the treatment of refractory ascites: a single-center experience. Langenbeck's Arch Surg 400:979-983

17. Bureau C, Adebayo D, de Rieu MC, Elkrief L, Valla D, Peck-Radosavljevic M et al Alfapump system vs. large volume paracentesis for refractory ascites: a multicenter randomized controlled study. J Hepatol

18. Solà E, Sanchez-Cabús S, Rodriguez E, Elia C, Cela R, Moreira R et al (2017) Effects of alfapump ${ }^{\mathrm{TM}}$ system on kidney and circulatory function in patients with cirrhosis and refractory ascites. Liver Transpl 23:583-593

19. Tan HK, James PD, Wong F (2016) Albumin may prevent the morbidity of paracentesis-induced circulatory dysfunction in cirrhosis and refractory ascites: a pilot study. Dig Dis Sci 61:3084-3092

20. Abdullah MH, Saleh SM, Morad WS Terlipressin versus norepinephrine to counteract intraoperative paracentesis induced refractory hypotension in cirrhotic patients. Egyptian Journal of Anaesthesia

21. Singh V, Kumar R, Nain CK, Singh B, Sharma AK (2006) Terlipressin versus albumin in paracentesis-induced circulatory dysfunction in cirrhosis: a randomized study. J Gastroenterol Hepatol 21:303-307

22. Moreau R, Asselah T, Condat B, de Kerguenec C, Pessione F, Bernard B et al (2002) Comparison of the effect of terlipressin and albumin on arterial blood volume in patients with cirrhosis and tense ascites treated by paracentesis: a randomised pilot study. Gut 50:90-94

23. Lata J, Marecek Z, Fejfar T, Zdenek P, Bruha R, Safka V et al (2007) The efficacy of terlipressin in comparison with albumin in the prevention of circulatory changes after the paracentesis of tense ascites--a randomized multicentric study. Hepato-gastroenterology 54:1930-1933

24. Singh V, Kumar B, Nain CK, Singh B, Sharma N, Bhalla A et al (2006) Noradrenaline and albumin in paracentesis-induced circulatory dysfunction in cirrhosis: a randomized pilot study. J Intern Med 260:62-68

25. Singh V, Dheerendra PC, Singh B, Nain CK, Chawla D, Sharma N et al (2008) Midodrine versus albumin in the prevention of paracentesis-induced circulatory dysfunction in cirrhotics: a randomized pilot study. Am J Gastroenterol 103:1399-1405

26. Appenrodt B, Wolf A, Grunhage F, Trebicka J, Schepke M, Rabe C et al (2008) Prevention of paracentesis-induced circulatory dysfunction: midodrine vs albumin. A randomized pilot study. Liver Int 28:1019-1025

27. Hamdy H, ElBaz AA, Hassan A, Hassanin O (2014) Comparison of midodrine and albumin in the prevention of paracentesis-induced circulatory dysfunction in cirrhotic patients: a randomized pilot study. J Clin Gastroenterol 48:184-188

28. Planas R, Gines P, Arroyo V, Llach J, Panes J, Vargas V et al (1990) Dextran-70 versus albumin as plasma expanders in cirrhotic patients with tense ascites treated with total paracentesis. Results of a randomized study. Gastroenterology 99:1736-1744

29. Gines A, Fernandez-Esparrach G, Monescillo A, Vila C, Domenech E, Abecasis $R$ et al (1996) Randomized trial comparing albumin, dextran 70, and polygeline in cirrhotic patients with ascites treated by paracentesis. Gastroenterology 111:1002-1010

30. Garcia-Compean D, Blanc P, Larrey D, Daures JP, Hirtz J, Mendoza E et al (2002) Treatment of cirrhotic tense ascites with Dextran-40 versus albumin associated with large volume paracentesis: a randomized controlled trial. Ann Hepatol 1:29-35

31. Moreau R, Valla DC, Durand-Zaleski I, Bronowicki JP, Durand F, Chaput JC et al (2006) Comparison of outcome in patients with cirrhosis and ascites following treatment with albumin or a synthetic colloid: a randomised controlled pilot trail. Liver Int 26:46-54

32. El-Ashry N, El-Damarawy M, Salem M, Mogawer S (2007) Large volume abdominal paracentesis effect on some humoral factors and cardiac performance in patients with liver cirrhosis and tense ascities. J Egypt Soc Parasitol 37:571-584

33. Abdel-Khalek EE, Arif SE (2010) Randomized trial comparing human albumin and hydroxyethyl starch $6 \%$ as plasma expanders for treatment of patients with liver cirrhosis and tense ascites following large volume paracentesis. Arab Journal of Gastroenterology 11:24-29

34. Nasr G, Hassan A, Ahmed S, Serwah A (2010) Predictors of large volume paracantesis induced circulatory dysfunction in patients with massive hepatic ascites. J Cardiovasc Dis Res 1:136-144

35. Cabrera J, Inglada L, Quintero E, Jimenez W, Losada A, Mayor J et al (1991) Large-volume paracentesis and intravenous saline: effects on the reninangiotensin system. Hepatology 14:1025-1028

36. Sola-Vera J, Minana J, Ricart E, Planella M, Gonzalez B, Torras X et al (2003) Randomized trial comparing albumin and saline in the prevention of paracentesis-induced circulatory dysfunction in cirrhotic patients with ascites. Hepatology 37:1147-1153

37. Spinella R, Sawhney R, Jalan R (2016) Albumin in chronic liver disease: structure, functions and therapeutic implications. Hepatol Int 10:124-132

38. Alessandria C, Elia C, Mezzabotta L, Risso A, Andrealli A, Spandre M et al (2011) Prevention of paracentesis-induced circulatory dysfunction in cirrhosis: standard vs half albumin doses. A prospective, randomized, unblinded pilot study. Dig Liver Dis 43:881-886

39. Hussain W, Khalid AB, Usmani T, Ghufran A, Shah H (2015) Low dose albumin for the prevention of renal impairment following large volume paracentesis in cirrhosis. Pakistan Journal of Medical Sciences 31:592-596

\section{Publisher's Note}

Springer Nature remains neutral with regard to jurisdictional claims in published maps and institutional affiliations. 